\title{
Superhydrophobic Al Surfaces with Properties of Anticorrosion and Reparability
}

\author{
Zhibing Zhan, ${ }^{\dagger}$ Zihao Li, $^{\dagger}$ Zhi Yu, ${ }^{\ddagger}$ Subhash Singh, ${ }^{\dagger \neq}$ and Chunlei Guo*, ${ }^{*}, \ddagger$ \\ ${ }^{\dagger}$ The Institute of Optics, University of Rochester, New York 14627, United States \\ ${ }^{\ddagger}$ Changchun Institute of Optics, Fine Mechanics and Physics (CIOMP), Changchun 130033, China
}

\section{Supporting Information}

ABSTRACT: Aluminum (Al) is one of the most widely used metals for industry and household applications, but its longevity is limited by its tendency for corrosion. In this work, we report a facile method to fabricate superhydrophobic $\mathrm{Al}$ surfaces that have excellent anti-corrosion effect. The surface is obtained by etching $\mathrm{Al}$ in $\mathrm{CuCl}_{2}$ solution to form the micro-nano-pit surface texture followed by lowering its surface energy in an aqueous ethanol solution of stearic acid. The superhydrophobic $\mathrm{Al}$ surfaces show water contact angles as high as $165^{\circ}$. Electrochemical tests demonstrate that the corrosion rate of the $\mathrm{Al}$ surface drops by $94.5 \%$ after the superhydrophobic modification (corrosion current density lowers from $1.11 \times 10^{-4}$ to $6.10 \times 10^{-6} \mathrm{~A} \mathrm{~cm}^{-2}$ ). We also
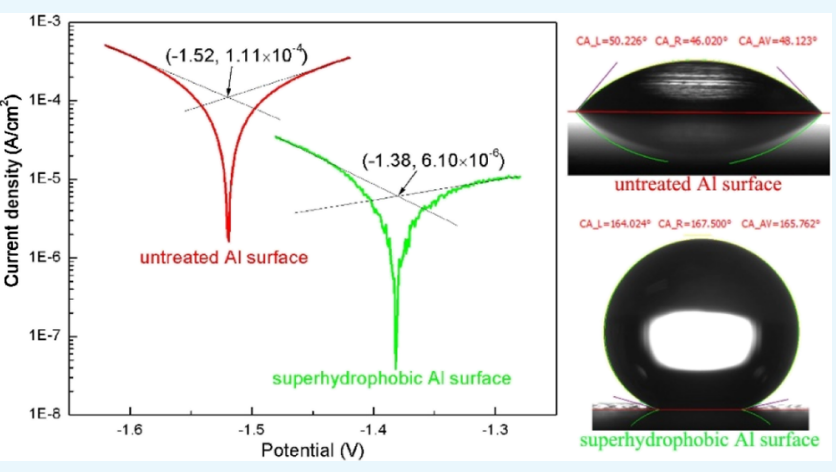
show that the superhydrophobic surface will protect the $\mathrm{Al}$ from corrosion even under a very harsh environment. In addition, our method is scalable and the superhydrophobic surfaces exhibit excellent flexible and reparable properties. This anti-corrosive superhydrophobic $\mathrm{Al}$ surface will prolong $\mathrm{Al}$ in its broad usage.

\section{INTRODUCTION}

Throughout the long-term evolution in nature, many organisms developed various characteristics with amazing properties. For instance, one such property is the superhydrophobicity of lotus leaves and water strider legs, which describes the nonwetting characteristics of material surfaces. $^{1-3}$ A superhydrophobic surface, normally defined as a surface with a water contact angle (an angle that a liquid makes with a solid) larger than $150^{\circ}$, repels water to form near spherical shapes that do not adhere to them but instead bounce off, which has attracted intensive attention because of its excellent prospects in the fields of self-cleaning, anti-icing, anti-corrosion, and microfluidic devices. ${ }^{4-14}$ As a light metal, aluminum (Al) has widely used in general industry as well as in household activities thanks to its excellent heat and electrical conductivities, natural availability, and high mechanical properties. ${ }^{15}$ However, these applications are seriously limited because of the easy corrosion or deterioration of $\mathrm{Al}$ surfaces. With the extensive nano- and micro-scale surface textures and a layer of air trapped among these structures, a superhydrophobic layer can repel the water and moisture from the surface, which results in a dry and clean surface., ${ }^{4,16}$ Consequently, superhydrophobic surfaces can slow down the corrosion or deterioration process on metal surfaces. ${ }^{7,8,17}$ It is therefore highly desirable to create a protective superhydrophobic Al surface with large area by facile and costeffective approaches. In this work, we report an easy method to produce superhydrophobic $\mathrm{Al}$ surfaces by etching in $\mathrm{CuCl}_{2}$ solution to form micro-nano-pit surface textures followed by lowering its surface energy in an aqueous ethanol solution of stearic acid. The fabricated superhydrophobic Al surfaces exhibit excellent properties of anticorrosion, flexibility, and reparability, which have significance to prolong $\mathrm{Al}$ materials in its broad usage.

\section{EXPERIMENTAL SECTION}

Al foils (Goodfellow, USA), copper(II) chloride (98\%, Alfa Aesar), stearic acid (98\%, Alfa Aesar), ethanol (absolute for analysis, Emsure, Merck KGaA, Darmstadt, Germany), sodium chloride (99\%, Alfa Aesar), and acetone (99.5\%, Alfa Aesar) were used for preparation of the superhydrophobic Al surfaces and characterization of the surface properties.

$\mathrm{Al}$ foils with the thickness of $\sim 0.2 \mathrm{~mm}$ were degreased in acetone and ethanol by using the ultrasonic method, and cleaned with deionized (DI) water. Then the cleaned Al foils were immersed in $\mathrm{CuCl}_{2}$ solution (5\%) to carry out the etching process. The etching process was stopped when the surface of the $\mathrm{Al}$ foil was totally etched (e.g., for an $\mathrm{Al}$ foil with a size of about $5 \mathrm{~cm}^{2}$ in $150 \mathrm{~mL} \mathrm{CuCl}$ solution, the suitable etching time is about $5 \mathrm{~min}$ ). During the etching process, ultrasonic was also used to remove the $\mathrm{Cu}$ particles aggregated on the $\mathrm{Al}$ foils. After the etching process, $\mathrm{Al}$ foils were first

Received: October 2, 2018

Accepted: December 6, 2018

Published: December 17, 2018 
rinsed with DI water and then ultrasounded with acetone for 10 min to remove the $\mathrm{Cu}$ particles finally. $\mathrm{Al}$ foils without $\mathrm{Cu}$ particles were dried by using nitrogen and immersed in an aqueous ethanol solution of stearic acid $(0.01 \mathrm{M})$ for $10 \mathrm{~min}$. After that, samples are rinsed by pure ethanol and kept in an oven at $60{ }^{\circ} \mathrm{C}$ for $1 \mathrm{~h}$, and cold in air for using.

Contact angle measurements were done by using a dropshape analyzer (Sl200KB, Kino, USA) with a droplet of distilled water having a drop volume of $0.2 \mu \mathrm{L}$. The experiments were repeated at five different points on each sample and the average values are calculated. Surface morphologies of samples were examined using scanning electron microscopy (Zeiss-Auriga Germany) and a confocal UV scanning laser microscope (KEYENCE, VK-9700).

To characterize anticorrosion property, the electrochemical measurements were performed by an electrochemical workstation ( $\mathrm{CHI} 680$ ) in $3.5 \mathrm{wt} \% \mathrm{NaCl}$ solution at the room temperature. The measurements were conducted in a threeelectrode cell with a $\mathrm{Ag} / \mathrm{AgCl}$ reference electrode and a platinum counter electrode. The sample with an exposed area of $1 \mathrm{~cm} \times 1 \mathrm{~cm}$ serves as the work electrode. Before the electrochemical measurements, all the samples were immersed in the $3.5 \mathrm{wt} \% \mathrm{NaCl}$ solution for $60 \mathrm{~min}$ to obtain a stable open circuit potential (OCP). Polarization curves were obtained for untreated and superhydrophobic $\mathrm{Al}$ surfaces by using a scan rate of $1 \mathrm{mV} / \mathrm{s}$ in the range of $\pm 100 \mathrm{mV}$ versus the OCP.

\section{RESULTS AND DISCUSSION}

The $\mathrm{Al}$ superhydrophobic surfaces are synthesized by two steps: first roughing the surface of a cleaned $\mathrm{Al}$ foil by chemical etching in $\mathrm{CuCl}_{2}$ solution (5\%), and then lowering the surface energy of the roughed $\mathrm{Al}$ foil by immersing into an aqueous ethanol solution of stearic acid $(0.01 \mathrm{M})$. Detailed fabrication processes are described in the experimental part. Figure $1 \mathrm{a}, \mathrm{b}$ shows the scanning electron microscope (SEM) images with sample photos (insets) of $\mathrm{Al}$ surfaces before and after $\mathrm{CuCl}_{2}$

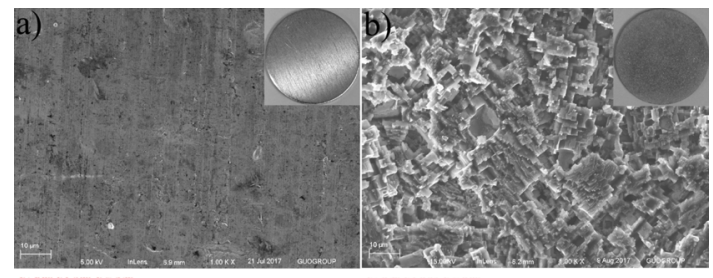

c)

d)

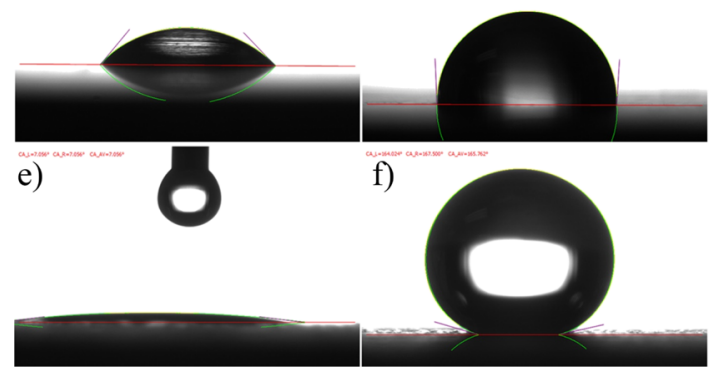

Figure 1. SEM images and sample photos (insets) of $\mathrm{Al}$ surfaces before (a) and after (b) $\mathrm{CuCl}_{2}$ etching. Contact angle measurement of the Al surface without surface roughness before (c) and after (d) stearic acid modification, and $\mathrm{Al}$ surface with surface roughness before (e) and after (f) stearic acid modification. etching. As can be seen, the chemical etching totally changes the morphologies of $\mathrm{Al}$ surfaces, which results in micro-nanopits on the surface of the $\mathrm{Al}$ foil. More SEM images with a large area or high magnification are shown in Supporting Information Figure S1. The cross section of laser microscope shown in Figure S2 demonstrate that the height of the micronano-pits variates to about $40 \mu \mathrm{m}$. The confocal UV laser microscope image of the three-dimensional surface profile can be found in Figure S3. These structures are essential for superhydrophobicity. Without the surface roughness, water static contact angles on the $\mathrm{Al}$ surface before and after stearic acid modification are only about $48^{\circ}$ and $90^{\circ}$, respectively, as shown in Figure 1c,d. Surface modification by stearic acid solution does not change the morphologies of $\mathrm{Al}$ foils, as shown in Figure S4. However, this modification is also very important to obtain the superhydrophobicity. The roughed $\mathrm{Al}$ surface without the chemical modification of stearic acid solution is totally hydrophilic. As shown in Figure 1e, water drops disperse immediately on the roughed Al surface upon impact, which makes it difficult to measure the static contact angle. After stearic acid modification on the rough $\mathrm{Al}$ surface, water static contact angle is found to be about $165^{\circ}$, as shown in Figure 1f. Surface modification to lower the surface energy with stearic acid solution results in the formation of a spongelike layer on the roughed $\mathrm{Al}$ surface due to the process of a carboxyl group that reacts with the $\mathrm{Al}$ atom through the following dehydration process:

$$
\mathrm{Al}^{3+}+3 \mathrm{CH}_{3}\left(\mathrm{CH}_{2}\right)_{16} \mathrm{COO}^{-} \rightarrow \mathrm{Al}\left(\mathrm{CH}_{3}\left(\mathrm{CH}_{2}\right)_{16} \mathrm{COO}\right)_{3}
$$

Bonding of the long nonpositive end of the alkyl to the roughed $\mathrm{Al}$ surface creates a low energy surface, which results in the final superhydrophobic property. ${ }^{15,18}$ This dehydration process is confirmed by our infrared spectra shown in Figure S5. The roll-off angles for the superhydrophobic surfaces are measured, which are less than $5^{\circ}$. Because of the excellent superhydrophobicity, when a drop of water is released and falls toward the superhydrophobic Al surface, the water droplet is repelled by the $\mathrm{Al}$ surface to such a degree that it bounces off the surface, lands again due to gravity, and bounces again and off the surface, as shown in Supporting Information Movie S1. Top- and side-view photos of a water drop locates on the surface of our prepared superhydrophobic Al foil are shown in Figure S6, which is very similar as a water drop on lotus leaves.

For the roughed $\mathrm{Al}$ surfaces after modification by stearic acid solution, water droplets could maintain a spherical shape on such surfaces with a water static contact angle of about $165^{\circ}$ (Figure 1f). The droplets are repelled by the modified $\mathrm{Al}$ surface, and could roll off with a very small angle (Movie S1). Therefore, the Al surface exhibits superhydrophobicity and ultralow adhesion to water droplets. The cooperation between the etching-induced roughness and the low-surface-energy stearic acid layer effectively inhibits the contact between the water droplet and the hierarchical micro- and nano-scale surface. The water droplet is at the Cassie-Baxter contact state. $^{6,7}$ The water droplet looks like being lifted by the hierarchical micro-nano-structures and touches just the top part of the structures. Therefore, the small contact area between the hierarchical structure and the water droplet leads to the superhydrophobicity of such roughed $\mathrm{Al}$ surfaces.

To check the mechanical durability of our superhydrophobic Al surfaces, we carried out the experiment of mechanical abrasion by using sandpaper (grit no. 400). As show in Figure $\mathrm{S} 7$, in one abrasion cycle, the $\mathrm{Al}$ surface with a weight of $50 \mathrm{~g}$ 

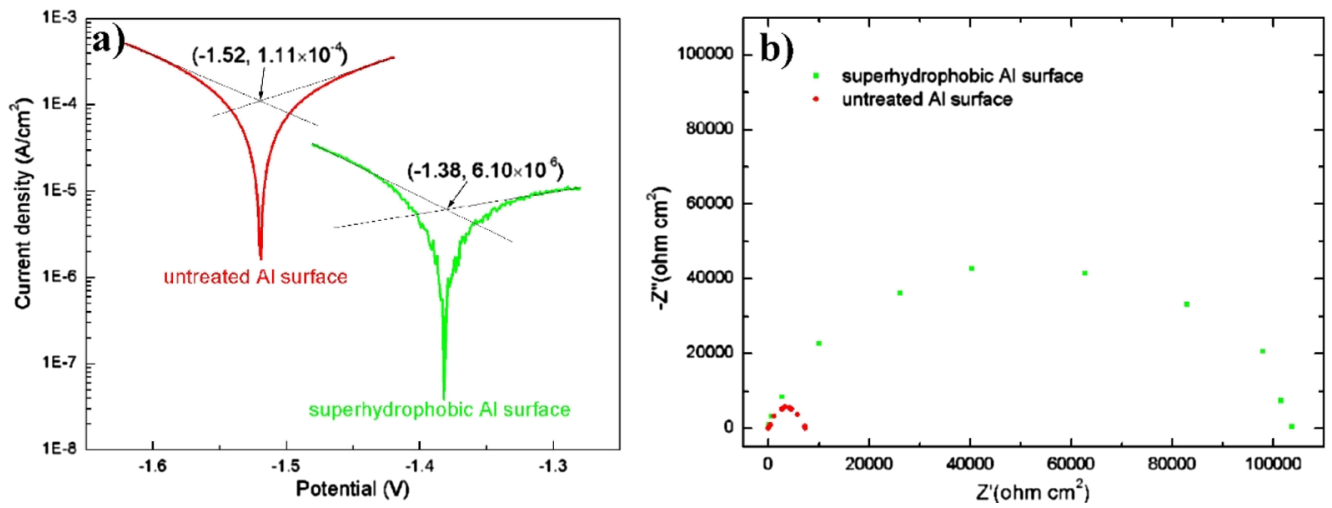

Figure 2. Tafel plots (a) and Nyquist plots (b) of the untreated $\mathrm{Al}$ surface and superhydrophobic $\mathrm{Al}$ surface in $3.5 \mathrm{wt} \% \mathrm{NaCl}$ solution.

Table 1. Corrosion Potential $\left(E_{\text {corr }}\right)$, Corrosion Current Density $\left(I_{\text {corr }}\right)$, Anodic Slope $\left(\beta_{\mathrm{a}}\right)$ and Cathodic Slope $\left(\beta_{\mathrm{c}}\right)$, CR and the CIE of the Untreated Al Surface and Superhydrophobic Al Surface

\begin{tabular}{lcccccc}
\multicolumn{1}{c}{ sample } & $E_{\text {corr }}(\mathrm{V})$ & $I_{\text {corr }}\left(\mathrm{A} \mathrm{cm}^{-2}\right)$ & $\beta_{\mathrm{a}}(\mathrm{mV} / \mathrm{dec})$ & $\beta_{\mathrm{c}}(\mathrm{mV} / \mathrm{dec})$ & $\mathrm{CR}(\mathrm{mm} /$ year $)$ & $\mathrm{CIE}(\%)$ \\
untreated Al & -1.52 & $1.11 \times 10^{-4}$ & 208.33 & 156.25 & 1.2099 & 0 \\
superhydrophobic Al & -1.38 & $6.10 \times 10^{-6}$ & 416.67 & 129.87 & 0.0665 & 94.5 \\
\hline
\end{tabular}

was placed face-down to a sandpaper and moved for $10 \mathrm{~cm}$ along the ruler; and then the sample was rotated by $90^{\circ}$ (face to the sandpaper) and moved for $10 \mathrm{~cm}$ along the ruler, which guarantees the surface is abraded longitudinally and transversely in each cycle. Our experiment shows that the $\mathrm{Al}$ surface can withstand at least 30 cycles of this sandpaper abrasion, which confirmed that the superhydrophobic Al surface has good mechanical durability to some extent.

In order to estimate the anti-corrosion property, Tafel plots were measured for untreated $\mathrm{Al}$ surface and superhydrophobic $\mathrm{Al}$ surface when the stable OCP was obtained after the samples being immersed into $\mathrm{NaCl}$ solution (3.5 wt \%) for at least 1 h. ${ }^{7,8}$ The measured Tafel plots are shown in Figure 2. On the basis of electrochemical kinetics of corrosion, the corrosion potential $\left(E_{\text {corr }}\right)$ and corrosion current density $\left(I_{\text {corr }}\right)$ can be obtained by the extrapolation method in this polarization (Tafel) plots. ${ }^{9,19-21}$ The ordinate and the abscissa of the intersection of anodic slope $\left(\beta_{\mathrm{a}}\right)$ and the cathodic slope $\left(\beta_{\mathrm{c}}\right)$ represented the $I_{\text {corr }}$ and $E_{\text {corr }}$ values, respectively, as shown in Figure 2. The fitting slopes of the linear parts in the Tafel plots at anodic and cathodic branches are $\beta_{\mathrm{a}}$ and $\beta_{\mathrm{c}}$ as shown in Figure S8. The values of the $E_{\text {corr }}, I_{\text {corr }}, \beta_{\mathrm{a}}$ and $\beta_{\mathrm{c}}$ derived from Tafel plots are summarized in Table 1 . We can find that the $E_{\text {corr }}$ and $I_{\text {corr }}$ of the untreated $\mathrm{Al}$ surface are about $-1.52 \mathrm{~V}$ and $1.11 \times 10^{-4} \mathrm{~A} \mathrm{~cm}^{-2}$, respectively. In comparison to the untreated $\mathrm{Al}$ surface, the $E_{\text {corr }}$ and $I_{\text {corr }}$ of the superhydrophobic $\mathrm{Al}$ surface reach about $-1.38 \mathrm{~V}$ and $6.10 \times 10^{-6} \mathrm{~A} \mathrm{~cm}^{-2}$, respectively. On the basis of electrochemical kinetics of corrosion, in such Tafel curves, a more positive $E_{\text {corr }}$ corresponds to a lower corrosion probability, while the $I_{\text {corr }}$ is a measurement of the corrosion rate (CR).,19,20 Therefore, this result demonstrates that superhydrophobic modification reduces both the corrosion probability and the $\mathrm{CR}$ of the $\mathrm{Al}$ surface obviously. The corrosion performance in our system is further evaluated by the electrochemical impedance spectroscopy (EIS) that is a powerful and complementary electrochemical technique. ${ }^{8}$ Figure $2 \mathrm{~b}$ is the EIS spectrum of the untreated $\mathrm{Al}$ surface and superhydrophobic $\mathrm{Al}$ surface by immersing in $3.5 \mathrm{wt} \% \mathrm{NaCl}$ solution. It is well known that a large Nyquist loop means a low CR. ${ }^{8}$ The diameter of the
Nyquist loop of the superhydrophobic Al surface is significantly larger than that of the normal Al surface, which indicates that the corrosion resistance has been greatly enhanced because of the superhydrophobic treatment.

On the basis of the obtained value of $I_{\text {corr }}\left(\mu \mathrm{A} / \mathrm{cm}^{2}\right)$, we can estimate the $\mathrm{CR}$ according to the following equations

$$
\mathrm{CR}(\mathrm{mm} / \text { year })=\frac{3.27 \times 10^{-3} \times I_{\text {corr }} \times M}{n d}
$$

where $M$ is the relative atomic mass of the metal $(\mathrm{g} / \mathrm{mol}), d$ is the density of the metal $\left(\mathrm{g} / \mathrm{cm}^{3}\right), n$ is the number of electrons required to oxidize an atom of the element in the corrosion process, that is, the valence of the metal, respectively. ${ }^{21,22}$ Also the corrosion inhibition efficiency (CIE) can be calculated according to the following equation

$$
\mathrm{CIE} / \%=\frac{I_{\text {corr }}-I_{\text {corr }}^{\prime}}{I_{\text {corr }}} \times 100
$$

$I_{\text {corr }}$ and $I_{\text {corr }}^{\prime}$ are the corrosion current densities before and after superhydrophobic modification for our $\mathrm{Al}$ surface, respectively. ${ }^{7}$ The calculated values of $\mathrm{CR}$ and CIE are also summarized on Table 1 . These electrochemical values demonstrate that the superhydrophobic modification really protects the surface of Al. The CR drops by $94.5 \%$ after the superhydrophobic surface treatment. The trapped air layer on the superhydrophobic surface diminishes the contact of water with the substrate interphase, which results in a barrier for the corrosion ions reaching the $\mathrm{Al}$ surface and corroding the metal. $^{7,8}$ Furthermore, the trapped air among the hierarchical micro- and nano-structures could repel the corrosion ions due to the Laplace pressure. ${ }^{7,8}$ Therefore, superhydrophobic modification can slow down the corrosion or deterioration process in the $\mathrm{Al}$ surface.

In order to check the anti-corrosion property of the $\mathrm{Al}$ superhydrophobic surface more directly, we tested the untreated $\mathrm{Al}$ foil and superhydrophobic $\mathrm{Al}$ foil under a harsh environment by using $\mathrm{CuCl}_{2}$ solution (5\%) as etching solution. Figure 3a shows the surfaces of the superhydrophobic and untreated $\mathrm{Al}$ foils before the etching test. Because of the strong diffusion of the roughed surface, the superhydrophobic $\mathrm{Al}$ foil 

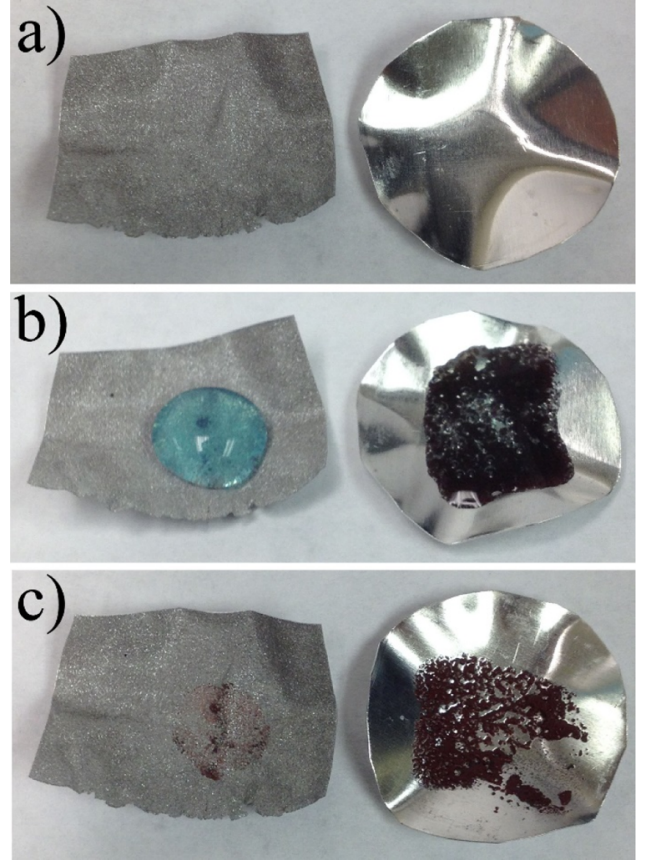

Figure 3. Photos of a superhydrophobic $\mathrm{Al}$ foil (rectangle sample at left side) and an untreated $\mathrm{Al}$ foil (round sample at right side) before (a) and after (b) etching by the same $\mathrm{CuCl}_{2}$ solution (5\%) for $65 \mathrm{~s}$, and after (c) pouring off the rest of the etching solution.

looks much darker than the untreated one. After etching by $\mathrm{CuCl}_{2}$ solutions with the same volume (4 drops) during the same time $(65 \mathrm{~s})$, these two $\mathrm{Al}$ foils display a totally different appearance. As shown in Figure 3b,c, the superhydrophobic Al surface only shows a very small etched area (the area with light brown color). By contrast, the untreated $\mathrm{Al}$ surface is etched seriously. Brown $\mathrm{Cu}$ particles are found obviously, which come from the etching of $\mathrm{CuCl}_{2}$ solution, as shown in Figure 3c. Detailed etching processes for these two foils can be seen clearly in supporting formation Movie S2. This experiment demonstrates undoubtedly that our superhydrophobic $\mathrm{Al}$ surface can slow down the corrosion of the $\mathrm{Al}$ foil even under a harsh environment.

Furthermore, our superhydrophobic Al surface is scalable. As shown in Figure 4a, it is fast and easy to fabricate such surface with a diameter of $10 \mathrm{~cm}$. In addition, the superhydrophobic $\mathrm{Al}$ surfaces exhibit excellent flexible and repairable properties. As can be seen in Figure 4, it still retains the superhydrophobic property after flattening the crumpled $\mathrm{Al}$ foil (Figure $4 \mathrm{a}-\mathrm{d}$ ). Also the superhydrophobic property on our $\mathrm{Al}$ surface can be repaired. As marked by the red arrows in Figure 4, the sandpaper-abraded areas exhibit obvious hydrophilic property (Figure 4e,f). However, this hydrophilic area can easily be repaired to superhydrophobicity after roughing the surface by $\mathrm{CuCl}_{2}$ solution etching and then lowering the surface energy by aqueous ethanol solution of stearic acid, which are described in experimental process and shown in Figure $4 \mathrm{~g}-\mathrm{j}$. It should be noted that, during the surface repairing process, the dropped $\mathrm{CuCl}_{2}$ solution only locates on the abraded hydrophilic area, as other areas are superhydrophobic (Figure 4h). After lowering the surface energy by dropping stearic acid solution, the superhydrophobic property recovers on these abraded hydrophilic areas (Figure 4i,j). This selectively repairable ability should have important significance for the
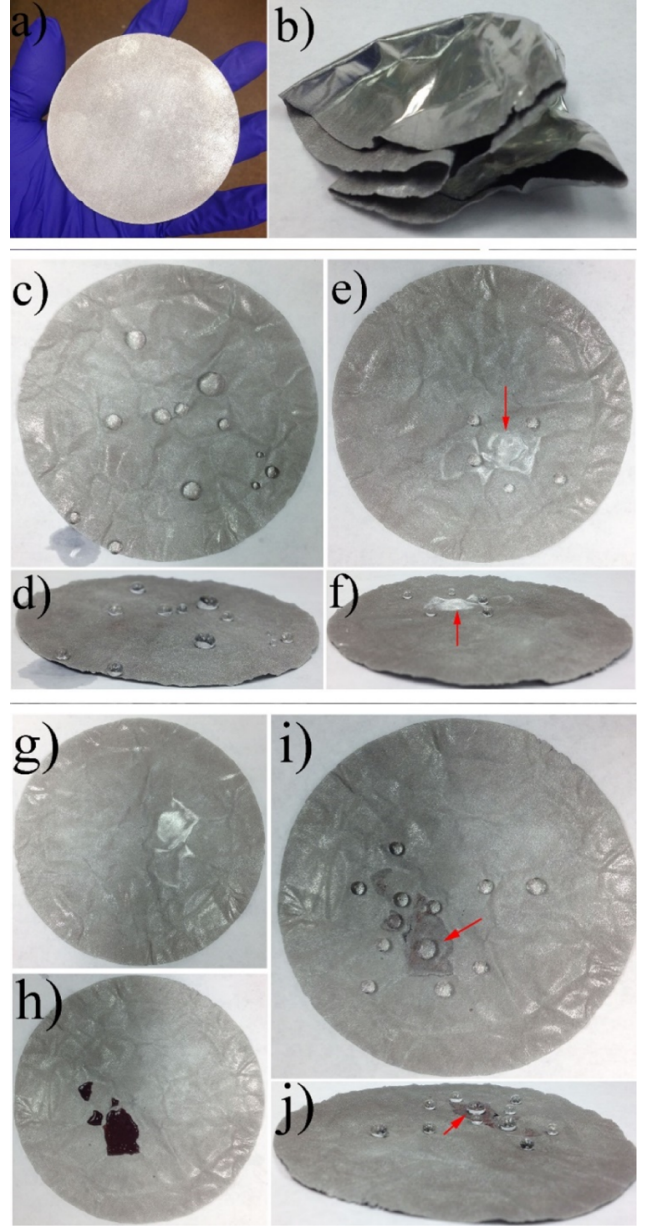

Figure 4. Photos of a superhydrophobic Al foil before (a) and after (b) crumpling; top-view (c) and side-view (d) photos of the $\mathrm{Al}$ foil after flattening with water drops; top-view (e) and side-view (f) photos of the $\mathrm{Al}$ foil with water drops and some areas abraded by the sandpaper show hydrophilic property (marked by red arrows); $(\mathrm{g})$ top-view photos of the $\mathrm{Al}$ foil without water drops and with some areas abraded by the sandpaper; (h) $\mathrm{Al}$ foil with abraded areas that are etching by $\mathrm{CuCl}_{2}$ solution; and (i) top-view and side-view ( $\mathrm{j}$ ) photos of the $\mathrm{Al}$ foil with water drops after superhydrophobic modification again (the repaired areas are marked by red arrows).

practical application of superhydrophobic $\mathrm{Al}$ surfaces as touching and damaging the surface is unavoidable in real usage.

\section{CONCLUSIONS}

In summary, superhydrophobic $\mathrm{Al}$ surfaces are fabricated by a simple approach, first etching in $\mathrm{CuCl}_{2}$ solution to form a micro-nano-pits surface texture and then lowering its surface energy in an aqueous ethanol solution of stearic acid. The modified Al surfaces show water contact angles as high as $165^{\circ}$. Electrochemical tests demonstrate that the $\mathrm{CR}$ of the $\mathrm{Al}$ surface drops by $94.5 \%$ after these treatments (corrosion current density lowers from $1.11 \times 10^{-4}$ to $6.10 \times 10^{-6} \mathrm{~A}$ $\mathrm{cm}^{-2}$ ). We also show that the superhydrophobic surface will protect the $\mathrm{Al}$ from corrosion even under a very harsh environment. In addition, our method is scalable and the superhydrophobic surfaces exhibit excellent flexible and reparable properties. This anti-corrosive superhydrophobic $\mathrm{Al}$ surface will prolong $\mathrm{Al}$ in its broad usage. 


\section{ASSOCIATED CONTENT}

\section{S Supporting Information}

The Supporting Information is available free of charge on the ACS Publications website at DOI: 10.1021/acsomega.8b02631.

Additional SEMs, laser microscopy images, photos, Tafel plots, and Movies of samples (PDF)

Release of a drop of water toward the superhydrophobic $\mathrm{Al}$ surface which is repelled by the $\mathrm{Al}$ surface (AVI)

Detailed etching processes for two foils (AVI)

\section{AUTHOR INFORMATION}

\section{Corresponding Author}

*E-mail: guo@optics.rochester.edu (C.G.).

ORCID $\odot$

Zhi Yu: 0000-0002-5139-0569

Chunlei Guo: 0000-0001-8525-6301

Notes

The authors declare no competing financial interest.

\section{ACKNOWLEDGMENTS}

This work was supported by the Bill \& Melinda Gates Foundation (OPP1119542), the US Army Research Office (W911NF-15-1-0319), and National Science Foundation (1701163 \& 1722169) grants.

\section{REFERENCES}

(1) Gao, X.; Jiang, L. Water-repellent legs of water striders. Nature 2004, 432, 36.

(2) Koh, J.-S.; Yang, E.; Jung, G.-P.; Jung, S.-P.; Son, J. H.; Lee, S.-I.; Jablonski, P. G.; Wood, R. J.; Kim, H.-Y.; Cho, K.-J. Jumping on water: Surface tension-dominated jumping of water striders and robotic insects. Science 2015, 349, 517.

(3) Ji, K.; Liu, J.; Zhang, J.; Chen, J.; Dai, Z. Super-floatable multidimensional porous metal foam integrated with a bionic superhydrophobic surface. J. Mater. Chem. A 2014, 2, 16589.

(4) Lu, Y.; Sathasivam, S.; Song, J.; Crick, C. R.; Carmalt, C. J.; Parkin, I. P. Robust self-cleaning surfaces that function when exposed to either air or oil. Science 2015, 347, 1132.

(5) Bird, J. C.; Dhiman, R.; Kwon, H.-M.; Varanasi, K. K. Reducing the contact time of a bouncing drop. Nature 2013, 503, 385.

(6) Feng, L.; Li, S.; Li, Y.; Li, H.; Zhang, L.; Zhai, J.; Song, Y.; Liu, B.; Jiang, L.; Zhu, D. Super-hydrophobic surfaces: From natural to artificial. Adv. Mater. 2002, 14, 1857.

(7) Vilaró, I.; Yagüe, J. L.; Borrós, S. Superhydrophobic Copper Surfaces with Anticorrosion Properties Fabricated by Solventless CVD Methods. ACS Appl. Mater. Interfaces 2016, 9, 1057.

(8) Xiang, T.; Han, Y.; Guo, Z.; Wang, R.; Zheng, S.; Li, S.; Li, C.; Dai, X. Fabrication of Inherent Anticorrosion Superhydrophobic Surfaces on Metals. ACS Sustainable Chem. Eng. 2018, 6, 5598.

(9) Argade, G. R.; Kandasamy, K.; Panigrahi, S. K.; Mishra, R. S. Corrosion behavior of a friction stir processed rare-earth added magnesium alloy. Corros. Sci. 2012, 58, 321.

(10) Oikawa, Y.; Saito, T.; Yamada, S.; Sugiya, M.; Sawada, H. Preparation and Surface Property of Fluoroalkyl End-Capped Vinyltrimethoxysilane Oligomer/Talc Composite-Encapsulated Organic Compounds: Application for the Separation of Oil and Water. ACS Appl. Mater. Interfaces 2015, 7, 13782.

(11) Ruan, C.; Ai, K.; Li, X.; Lu, L. A Superhydrophobic Sponge with Excellent Absorbency and Flame Retardancy. Angew. Chem., Int. Ed. 2014, 53, 5556.

(12) Hou, X.; Wang, X.; Zhu, Q.; Bao, J.; Mao, C.; Jiang, L.; Shen, J. Preparation of polypropylene superhydrophobic surface and its blood compatibility. Colloids Surf., B 2010, 80, 247.
(13) Guo, J.; Yu, S.; Li, J.; Guo, Z. Fabrication of functional superhydrophobic engineering materials via an extremely rapid and simple route. Chem. Commun. 2015, 51, 6493.

(14) Mayser, M. J.; Barthlott, W. Layers of Air in the Water beneath the Floating Fern Salvinia are Exposed to Fluctuations in Pressure. Integr. Comp. Biol. 2014, 54, 1001.

(15) Varshney, P.; Mohapatra, S.; Kumar, A. Fabrication of Mechanically Stable Superhydrophobic Aluminium Surface with Excellent Self-Cleaning and Anti-Fogging Properties. Biomimetics 2017, 2, 2.

(16) Tian, X.; Verho, T.; Ras, R. H. A. Moving superhydrophobic surfaces toward real-world applications. Science 2016, 352, 142.

(17) Ferrari, M.; Benedetti, A. Superhydrophobic surfaces for applications in seawater. Adv. Colloid Interface Sci. 2015, 222, 291.

(18) Wang, G.; Liu, S.; Wei, S.; Liu, Y.; Lian, J.; Jiang, Q. Robust superhydrophobic surface on $\mathrm{Al}$ substrate with durability, corrosion resistance and ice-phobicity. Sci. Rep. 2016, 6, 10.

(19) Barkhudarov, P. M.; Shah, P. B.; Watkins, E. B.; Doshi, D. A.; Brinker, C. J.; Majewski, J. Corrosion inhibition using superhydrophobic films. Corros. Sci. 2008, 50, 897.

(20) Zhang, X. L.; Jiang, Z. H.; Yao, Z. P.; Song, Y.; Wu, Z. D. Effects of scan rate on the potentiodynamic polarization curve obtained to determine the Tafel slopes and corrosion current density. Corros. Sci. 2009, 51, 581.

(21) Jones, D. A. Principles and Prevention of Corrosion; Prentice-Hall Inc.: New Jersey, 1996.

(22) Groysman, A. Corrosion for Everybody; Springer-Verlag Berlin: Berlin, 2010. 